\title{
MATERIALS AND COMPONENT DEVELOPMENT FOR ADVANCED TURBINE SYSTEMS
}

\author{
M. A. Alvin \\ National Energy Technology Laboratory \\ 626 Cochrans Mill Road, Pittsburgh, PA 15236-0940 \\ Phone: 412-386-5498; Fax: 412-386-4806; email: maryanne.alvin@netl.doe.gov \\ F. Pettit, G. Meier, M. Yanar, M. Helminiak \\ M. Chyu, S. Siw, W. Slaughter, V. Karaivanov \\ National Energy Technology Laboratory \& \\ Mechanical Engineering and Material Science \\ University of Pittsburgh, Pittsburgh, PA 15260

\section{B. Kang, C. Feng, J. M. Tannebaum} \\ R. Chen, B. Zhang, T. Fu \\ National Energy Technology Laboratory \& \\ Mechanical and Aerospace Engineering \& Civil and Environmental Engineering \\ West Virginia University, Morgantown, WV 26506
G. Richards, T. Sidwell, D. Straub, K. Casleton
O. Dogan \\ National Energy Technology Laboratory \\ Morgantown, WV 26506 \& Albany, OR 97321
}

\begin{abstract}
Hydrogen-fired and oxy-fueled land-based gas turbines currently target inlet operating temperatures of 1425$1760^{\circ} \mathrm{C}\left(\sim 2600-3200^{\circ} \mathrm{F}\right)$. In view of natural gas or syngas-fired engines, advancements in both materials, as well as aerothermal cooling configurations are anticipated prior to commercial operation. This paper reviews recent technical accomplishments resulting from NETL's collaborative research efforts with the University of Pittsburgh and West Virginia University for future land-based gas turbine applications.
\end{abstract}

\section{INTRODUCTION}

Future hydrogen-fired or oxy-fuel turbines will likely experience an enormous level of thermal and mechanical loading, as the turbine inlet temperature (TIT) may rise above $1700^{\circ} \mathrm{C}\left(3092^{\circ} \mathrm{F}\right)$ with pressures of 40 bars (Table 1). The estimated thermal loading or heat flux imposed on a turbine airfoil would be about 10 times the level in the current state-of-the art gas turbines. To maintain the structural integrity of turbine components under such an extreme condition requires (1) high temperature creep resistant metal substrates, (2) durable thermal barrier coatings (TBC), and (3) effective cooling techniques. While advances in substrate materials have been limited for the past decades, thermal protection of turbine airfoils in future hydrogen-fired and oxy-fuel turbines will rely primarily on collective advances in TBC and cooling.

This project supports a comprehensive effort conducted principally through NETL's Office of Research and Development (ORD) to generate a wrap-around knowledge-based understanding of turbine materials and aerothermal systems for utilization in advanced land-based turbine applications as the hydrogen-fired and oxy-fueled turbines. This initiative which began in FY07 focuses on the efforts undertaken at NETL-Pittsburgh which

- $\quad$ Combines the expertise of NETL, University of Pittsburgh (UPitt), and West Virginia University (WVU) researchers, working in conjunction with commercial metal and coating suppliers as Howmet International 
and Coatings for Industry (CFI) to develop advanced material systems, as well as non-destructive evaluation diagnostic techniques.

- Combines the expertise of the UPitt and NETL to develop advanced aerothermal cooling and computational creep life prediction models, and to demonstrate the validity of advanced cooling concepts in bench-scale laboratory test facilities that are currently being designed and constructed on NETL's and the University's campuses.

- Utilizes test facilities at Westinghouse Plasma Corporation (WPC) for high temperature thermal flux testing, and Praxair's JETS testing for evaluation of newly developed material systems in conjunction with developing baseline reference performance characteristics for commercial state-of-the-art TBC-coated material systems.

A brief summary of major technical accomplishments that have been achieved during conduct of this project is presented in the following sections.

TABLE 1

ADVANCED TURBINE OPERATING CONDITIONS [1]

\begin{tabular}{|c|c|c|c|c|}
\hline & $\begin{array}{c}\text { Syngas Turbine } \\
\mathbf{2 0 1 0}\end{array}$ & $\begin{array}{c}\text { Hydrogen Turbine } \\
\mathbf{2 0 1 5}\end{array}$ & $\begin{array}{c}\text { Oxy-Fuel Turbine } \\
\mathbf{2 0 1 0}\end{array}$ & $\begin{array}{c}\text { Oxy-Fuel Turbine } \\
\mathbf{2 0 1 5}\end{array}$ \\
\hline $\begin{array}{c}\text { Combustor Exhaust } \\
\text { Temp, }{ }^{\circ} \mathbf{C}\left({ }^{\circ} \mathbf{F}\right)\end{array}$ & $\sim+1480$ & $\sim+1480$ & & \\
\hline Turbine Inlet Temp, & $\sim+2700)$ & $(\sim+2700)$ & & \\
${ }^{\circ} \mathbf{C}\left({ }^{\circ} \mathbf{F}\right)$ & $(1370$ & $\sim 1425$ & $\sim 620$ & $\sim 760(\sim 1400)(\mathrm{HP})$ \\
\hline Turbine Exhaust & $\sim 2500)$ & $(\sim 2600)$ & $(\sim 1150)$ & $\sim 1760(\sim 3200)(\mathrm{IP})$ \\
Temp, ${ }^{\circ} \mathbf{C}\left({ }^{\circ} \mathbf{F}\right)$ & $(\sim 1100)$ & $\sim 595$ & & \\
\hline Turbine Inlet & $\sim 265$ & $(\sim 1100)$ & & $\sim 1500(\mathrm{HP})$ \\
Pressure, psig & & $\sim 300$ & & $\sim 625(\mathrm{IP})$ \\
\hline Combustor Exhaust & $9.27 \% \mathrm{CO}_{2}$ & $1.4 \% \mathrm{CO}_{2}$ & $82 \% \mathrm{H}_{2} \mathrm{O}$ & $75-90 \% \mathrm{H}_{2} \mathrm{O}$ \\
Composition & $8.5 \% \mathrm{H}_{2} \mathrm{O}$ & $17.3 \% \mathrm{H}_{2} \mathrm{O}$ & $17 \% \mathrm{CO}_{2}$ & $25-10 \% \mathrm{CO}_{2}$ \\
& $72.8 \% \mathrm{~N}_{2}$ & $72.2 \% \mathrm{~N}_{2}$ & $0.1 \% \mathrm{O}_{2}$ & $1.7 \% \mathrm{O}_{2}, \mathrm{~N}_{2}, \mathrm{Ar}$ \\
& $0.8 \% \mathrm{Ar}$ & $0.9 \% \mathrm{Ar}$ & $1.1 \% \mathrm{~N}_{2}$ & \\
\hline
\end{tabular}

TECHNICAL ACCOMPLISHMENTS

\section{TURBINE MATERIALS DEVELOPMENT}

Current commercial thermal barrier coating (TBC) systems consist of nickel-base superalloy or single-crystal substrates coated with MCrAlY ( $\mathrm{M}=\mathrm{Ni}$, Co) or a diffusion aluminide bond coat which forms an alumina layer (thermally-grown oxide, TGO), on to which is deposited yttria-stabilized zirconia (YSZ). The YSZ TBC layer can be applied by air plasma spraying (APS) generally to thicknesses between 200 to $300 \mu \mathrm{m}$, or by electron beam physical vapor deposition (EBPVD) to thicknesses of $\sim 100$ to $125 \mu \mathrm{m}$. EBPVD coatings are used for the most demanding applications, such as the leading edges of airfoils.

The YSZ TBCs are applied to components for the purpose of insulation rather than oxidation protection. The use of an insulating coating coupled with internal air cooling of the component, lowers the surface temperature of the component with a corresponding decrease in the creep and oxidation rates of the component. Use of TBCs has resulted in a significant improvement in the efficiency of gas turbines. 
Efforts in the Turbine Materials Development technology area of this project have been focused on (1) development of a wet spray bond coat system that can be applied to nickel-based superalloys and single crystal substrates, and integrated with YSZ as either a discrete layer or as a functional gradient, (2) provision of higher thermal insulating capabilities of the external YSZ layer through development and application of thicker APS YSZ layers with improved subsurface bond coatings, and (3) development of advanced substrate materials based on aeroengine technology utilizing niobium-based systems. Areas 2 and 3 support extended airfoil life in the event that adequate metal substrate surface temperatures are not adequately cooled, or that failure of the applied TBC layer occurs during operation in future gas turbine applications.

\section{Bond Coat Development}

In the development of thermal barrier coatings (TBC), high temperature (i.e., $1100^{\circ} \mathrm{C}$; $\left(2012^{\circ} \mathrm{F}\right)$ ) thermal cycle testing in static air is typically used as an initial screening tool to assess the potential performance of new material systems. Prior efforts using the high temperature bottom loading furnaces at the University of Pittsburgh (UPitt) have demonstrated that the cycle-to-failure lifetime of the newly developed NETL/CFI wet-spray bond coat systems with commercially applied EBPVD YSZ top coats exceeds the cycle-to-failure lifetime of a state-of-the-art (SOTA) NiCoCrAlY/YSZ system. The NETL/YSZ system has, however, only achieved $61 \%$ of the cycle-to failure lifetime of PtAl/YSZ systems. Efforts will continue to be focused on improvement of the $1100^{\circ} \mathrm{C}\left(2012^{\circ} \mathrm{F}\right)$ cyclic life of the NETL/CFI bond coat system through the addition of reactive elements. Efforts will also be focused on modification of the bond coat surface roughness characteristics to improve adherence of APS YSZ systems. Pending bottom loading furnace test results, testing of the NETL/CFI bond coat with an applied APS YSZ layer on tubular René N5 substrates will be conducted at high temperature under thermal flux at rotational speeds of $\sim 500 \mathrm{rpm}$ at Westinghouse Plasma Corporation (WPC). To further complete NETL's reference database for comparison of extended, high temperature, oxidative stability of bond coat systems, exposure of commercially fabricated CoNiCrAlY/NiCoCrAlY systems will be undertaken. Similarly material systems provided by OEMs as Pratt \& Whitney will be characterized and assessed in terms of $1100^{\circ} \mathrm{C}\left(2012^{\circ} \mathrm{F}\right)$ cycle-to-failure life.

\section{APS TBC Development}

Hydrogen fuel technologies leading to near zero emission power plants involve a transition from gas turbines operating with syngas with properties of those produced at current IGCC plants, to very high hydrogen fuels derived from syngas, to syngas burned in nearly pure oxygen using steam to control temperatures (oxy-fuel systems). Higher gas turbine inlet operating temperatures (i.e., $\left.\sim 1425-1760^{\circ} \mathrm{C}\left(\sim 2597-3200^{\circ} \mathrm{F}\right)\right)$ are projected for future hydrogen-fired and oxy-fueled applications, and therefore it is anticipated that improved, higher temperature, thermal barrier coating (TBC) systems will be needed.

There has been some progress in identifying oxides with lower thermal conductivities than the commercially used 7YSZ TBCs. These oxides, however, do not have the balance of properties necessary for use in the advanced turbine applications. An alternate approach is to improve the adherence, as well as increase the applied thickness of APS TBCs, and improve the underlying bond coat properties on nickel-based superalloys for turbine blades, vanes, and combustor components. Accomplishments to date at UPitt have (1) demonstrated viability of $375 \mu \mathrm{m}$ APS applied to MCrAlY/IN 718 after 2,000 test cycles in the Praxair JETS test rig; (2) demonstrated TBC through-wall gradients of $350^{\circ} \mathrm{C}, 395^{\circ} \mathrm{C}$, and $550^{\circ} \mathrm{C}$, respectively for $375 \mu \mathrm{m}, 750 \mu \mathrm{m}$, and $1125 \mu \mathrm{m}$ APS layers; (3) demonstrated high temperature sintering resistance of the high purity YSZ; and (4) demonstrated that failure in YSZ is primarily along splat boundaries. Future efforts will include: Continued microstructural characterization of as-manufactured and failed TBCs on René N5 and HA 188; Establishment of the mechanical properties (i.e., modulus of elasticity; fracture strength as a function of temperature; thermal conductivity) of as-processed and tested matrices; Identification of the optimized bond coat and top coat processing parameters; Comparison of the performance to state-of-the-art EBPVD and segmented plasma spray coatings; Preparation of solution spray precursor TBCs (Univ.Conn). 


\section{Substrate Development}

The objectives of this effort are to assess the potential use of experimental refractory metal-based alloys that have shown promise for aero-engine gas turbine applications, for future land-based gas turbine applications. Nb-based superalloys were identified as candidate materials where substrate materials experience temperatures of 1300$1500^{\circ} \mathrm{C}\left(2372-2732^{\circ} \mathrm{F}\right)$. One candidate alloy - 58Nb-15Al-8Y-7Pt-6Ti-3Hf-3Cr at\% [2] — has recently been produced by Pittsburgh Materials Technologies (PMT), and is being evaluated in terms of alloy composition and microstructure at NETL-Albany. Efforts that are planned to be undertaken in FY09 include: Bench-scale testing to evaluate the corrosion/oxidation resistance of candidate substrate matrices at $1300-1450^{\circ} \mathrm{C}\left(2372-2642^{\circ} \mathrm{F}\right)$ in both moist and dry environments; Identification of potential alloy development strategies to improve substrate material performance; Combination of computational material science (i.e., first principles, thermodynamics, kinetics calculations) and experimentation, addressing generation of less expensive alloying elements to achieve oxidation and creep resistance; Production of candidate, advanced, high temperature, land-based gas turbine alloys at NETLAlbany.

\section{AEROTHERMAL HEAT TRANSFER}

Efforts in the Aerothermal Heat Transfer technology area that were undertaken in FY07 and FY08 included development of a three-dimensional computational simulation of external heat transfer and thermal loading over a generic turbine airfoil for the hydrogen-fired and oxy-fuel turbine applications. Information from this simulation provided detailed local distributions of surface temperature and heat flux penetrating through the TBC layer. In conjunction with solid modeling, the metal substrate temperature, and local stress and strain over the entire airfoil were also determined. Complementary to the aerothermal modeling in FY08 was the development of a durabilitylife prediction methodology for TBC coated systems. This unique approach, based on damage mechanics for crack formation and propagation, is capable of transforming a group of operating variables (i.e., temperature, stress, strain, and moisture), to quantifying the durability and life prediction for both the substrate matrix and TBC.

To confirm the computational modeling efforts that were undertaken at UPitt, three bench-scale experimental test facilities are being constructed to address potential technology advancements for both external and internal cooling concepts, as well as validation of the damage mechanics concepts for evolution of TBC damage.

\section{External Heat Transfer Modeling}

During FY08, a systematic effort was conducted to explore potential internal cooling arrangements and their impact on the stress/strain distributions over realistic configurations of hydrogen-fired and oxy-fuel airfoils [3-6]. These configurations included the multiple-pass serpentine cooling passage in the generic NASA $\mathrm{E}^{3}$ airfoil, as well as a skin cooled architecture. The influence on the thermal characteristics across the TBC layer, and its implication to the TBC effectiveness and reliability were also addressed.

In summary, the major technical accomplishments achieved during the FY08 efforts include the following:

- The current aerothermal model projects similar pressure and temperature distribution trends for hydrogenfired and oxy-fuel airfoil as those under convection dominated flow.

- External gas compositions containing a higher steam content leads to higher heat transfer coefficients. For example, the heat transfer coefficient for oxy-fuel systems containing $75-90 \%$ steam is $\sim 40 \%$ higher than the heat transfer coefficient for hydrogen-fired systems containing $17 \%$ steam.

- Internal cooling significantly impacts the substrate metal temperature. A 3-fold increase in the internal $\mathrm{h}_{\mathrm{c}}$ decreases the metal surface temperature by $\sim 150-200^{\circ} \mathrm{C}$ for the hydrogen-fired airfoils.

- Internal heat transfer coefficients are projected to be gradually reduced from the leading edge towards the trailing edge.

- Utilization of skin cooling configurations reduces the metal surface temperature by $\sim 50-100^{\circ} \mathrm{C}$.

- If complete spallation of the TBC occurs, the surface metal temperature is projected to increase by $\sim 200$ $250^{\circ} \mathrm{C}$. 
An important conclusion from the FY08 modeling effort is that internal cooling alone will be insufficient to provide future land-based turbines with adequate cooling for viable extended operation using current commercial superalloys and single crystal substrate materials. This is particularly the case near the turbine airfoil edges (i.e., leading edge, trailing edge and tip region), and certain local hot spots. As a result, external cooling (i.e., film cooling and the like), is necessary, and will be the focus of future aerothermal activities.

\section{Airfoil Life Prediction Modeling}

Durability designs and component life assessment for advanced turbine airfoils subjected to high rotational speeds and gas temperatures requires an in-depth understanding of thermal-mechanical coupling on the metal substrate fatigue and creep damage mechanisms and damage mechanisms within the TBC. During FY08, finite element and damage mechanics models were developed in conjunction with the turbine materials development efforts, to analyze the effects on damage evolution of different cooling concepts, in an effort to predict which combinations of TBC thermal conductivity and internal convective cooling strategies are most effective at mitigating damage.

The current creep damage model includes the effects of stress relaxation, and a centrifugal load of 3,600 rpm, for an airfoil base radius of $0.6 \mathrm{~m}$. The model has incorporated compact TGO growth, and inward growth and phase depletion at the airfoil outer boundary. For airfoils consisting of a 1,000 $\mu \mathrm{m}$ CMSX-4 substrate, a $125 \mu \mathrm{m}$ MCrAlY bond coat, and a $250 \mu \mathrm{m}$ YSZ top coat layer, the following are projected:

- Hydrogen-Fired System: After 1,000 hrs, limited creep damage is projected to occur along the pressure surface of middle-rib; Extensive middle rib creep damage occurs after 4,000 hrs with damage along the suction surface rib near the trailing edge.

- Oxy-Fuel System: After $10 \mathrm{hrs,} \mathrm{extensive} \mathrm{creep} \mathrm{damage} \mathrm{is} \mathrm{projected} \mathrm{to} \mathrm{occur} \mathrm{along} \mathrm{the} \mathrm{suction} \mathrm{surface} \mathrm{of}$ the airfoil near the leading edge, middle rib pressure surface, and at the base of the airfoil.

In conjunction with model development, laboratory-scale experimental validation is being undertaken to verify the viability of the underlying damage mechanics concepts for the evolution of TBC damage. Verification relies on simple coupon geometries (i.e., $2.54 \mathrm{~cm} \times 2.54 \mathrm{~cm} \times 0.635 \mathrm{~cm}$ coupons provided by NETL) made from representative nickel-based single-crystal René N5 matrices, coated with TBC systems (MCrAlY/APS YSZ), and loaded under conditions that represent those found in service. The coupons are initially subjected to NDE techniques (Enabling Technologies section), and are subsequently subjected to uniaxial compressive stress at elevated temperatures (i.e., $900-1100^{\circ} \mathrm{C}$ ) for a maximum of 3,000 hrs to observe the effect on the TBC system. The effect of varying TGO thickness is also being assessed. The experimental results will be compared with the predictions from the finite element and damage mechanics models. This effort will attempt to further clarify the effect that creep strain in the substrate has on the evolution of various forms of damage within the TBC system.

\section{Aerothermal Test Facilities}

Two test facilities are currently being developed by UPitt to explore aerothermal cooling of airfoils for use in advanced, land-based, turbine applications. In joint development with NETL, the aerothermal rig in Morgantown is a heat transfer testing facility capable of providing realistic turbine flow conditions with elevated temperature and pressure. Upstream to the aerothermal test section is a combustor capable of burning a variety of fuels, including natural gas, syngas, and hydrogen. As the planned research is directed primarily to advanced IGCC and clean coal applications, all tests will be performed with gas compositions simulating the syngas and hydrogen-fired conditions with a flame temperature at $\sim 1627^{\circ} \mathrm{C}\left(\sim 2960^{\circ} \mathrm{F}\right)$. Initially, test coupons $(\sim 5 \mathrm{~cm} \mathrm{x} \sim 5 \mathrm{~cm} \mathrm{x} \sim 0.64 \mathrm{~cm})$ will be exposed to the hot combustion gas with adequate backside cooling. The temperature distribution over the coupon surface will be acquired using a pyrometer and CCD camera with a band-pass filter. The hot gas temperature is measured through the hyperspectral imaging system by using a mid infra-red spectrometer. Following the heat transfer tests with flat coupons, the effects of film cooling over the test coupon will be systematically explored. The test as such is particularly valuable for preserving adequate density ratio between the film injectant and freestream. The fidelity of gas compositions can also be preserved, which is otherwise unattainable by most of the facilities operated under scaled temperature and pressure conditions. To simulate the oxy-fuel operating conditions with highly enriched steam (85\%), additional steam lines will need to be installed. 
The aerothermal test rig at UPitt will explore the potential of use of steam and/or carbon dioxide $\left(\mathrm{CO}_{2}\right)$ as the working media for internal cooling of future airfoil configurations. Saturated steam obtained from the in-house steam line at $\sim 130^{\circ} \mathrm{C}$ will be heated to $\sim 250^{\circ} \mathrm{C}$ as a flowing media in the rig. Initially, the heat transfer characteristics of superheated steam will be investigated using a rectangular test section with an aspect ratio $\mathrm{W} / \mathrm{H}=$ 3. The heat transfer profile from a smooth surface obtained during the initial phase of testing will serve as a baseline for subsequent efforts. Temperature distributions over the test section will be monitored and captured using an infrared camera with a ZnSe optical window. The bulk temperature of the superheated steam flow will be monitored using type-K thermocouples connected to a data acquisition system. In the second phase of this effort, roughened surfaces, pin fins, and other vortex generators elements will be implemented and the resulting heat transfer enhancement will be measured. Subsequently, an additional line with carbon dioxide will be added to the test rig, permitting assessment of the effects of steam and carbon dioxide mixtures on the internal cooling of future advanced turbine airfoils.

\section{ENABLING TECHNOLOGIES}

Monitoring the stability or degradation of commercial TBCs or developmental material systems has been traditionally conducted via destructive analyses of numerous coupon samples. Frequently, however, destruction of coupons or full airfoils is not warranted since continued exposure or in-service use is required. Therefore development of non-destructive evaluation techniques is considered to be essential for assessment of extended component life. The objectives of the Enabling Technologies effort are to develop a micro-indentation methodology/technique/equipment to assess the residual stiffness of TBC coatings on flat, as well as curved surfaces (i.e., leading edge of the airfoil; tubular samples used in the Turbine Materials Development effort of this project) to project material/component performance longevity and/or impending spallation of the applied protective coatings. Acousto-ultrasonic diagnostics are viewed as an additional technique to address material system and/or component life. To facilitate this effort and maintain continuity within the project and its primary objectives, NETL has provided bond coated coupons, as well as commercially applied TBC systems to WVU for their development efforts.

\section{Micro-Indentation Testing}

A micro-indentation technique is being developed at WVU for determining mechanical property degradation and possible debonding/spallation of thermal barrier coatings during extended service life. To date, use of the microindentation technique has confirmed the reported Young's Modulus for Hayne 230, and has projected similar material properties for René N5. Additionally, after 400 thermal cycles at $1100^{\circ} \mathrm{C}\left(2012^{\circ} \mathrm{F}\right)$, the surface stiffness of the NETL- 1 bond coat was shown to be reduced by $\sim 41.7 \%$ on René N5, and $\sim 62.5 \%$ on Haynes 230 . These data were seen to be strongly correlated with weight and microstructural changes identified for each system under the Turbine Materials Development efforts [7]. Currently, complete surface stiffness contour profiles are being developed for commercially manufactured MCrAlY/EBPVD and MCrAlY/APS coatings applied to the surface of René N5 and Haynes 230 coupons. During the initial 20 high temperature $\left(1100^{\circ} \mathrm{C} ; 2012^{\circ} \mathrm{F}\right)$ thermal cycles, a reduction in surface stiffness of $\sim 15.1 \%$ and $\sim 2.8 \%$ respectively, was determined.

Efforts are planned to continue to monitor and correlate the loss of surface stiffness with microstructural changes that occur in commercially-coated TBC material systems that are exposed to extended thermal cycling at $1100^{\circ} \mathrm{C}$ $\left(2012^{\circ} \mathrm{F}\right)$. Measured surface stiffness contour profiles will similarly be used to address TGO growth and eventual interfacial debonding/spallation along test coupon surfaces, facilitating development of the micro-indentation technique to detect initiation of cycle-to-failure life of TBC systems.

Additionally, the capability of the newly developed, hand-held, micro-indentation unit will be demonstrated and assessed in terms of data generated from the original stationary and portable devices, and where possible, on process-exposed substrates or at on-site field applications. Similarly, utilization of the micro-indentation units will be demonstrated for curved surfaces, as well as at elevated temperatures (i.e., initially at $600-800^{\circ} \mathrm{C}\left(1112-1472^{\circ} \mathrm{F}\right.$ ); potentially with follow-on to $\left.\sim 1100^{\circ} \mathrm{C}\left(2012^{\circ} \mathrm{F}\right)\right)$. 


\section{Non-Linear Acousto-Ultrasonic Diagnostics}

A nonlinear acousto-ultrasonic technique is being developed at WVU to evaluate interface delamination of bond coating and YSZ top coat systems that are applied to the surface of single crystal and superalloy metal substrates. A greater nonlinear response in the waveform amplitude-dependent characteristics is projected to result when debonding/delamination of the coatings occurs. To date, piezoelectric sensor with dry contact has generated waveforms that detect minor changes within the NETL-1 bond coat applied to René N5 after 400-500 hours of cyclic oxidation at $1100^{\circ} \mathrm{C}\left(2012^{\circ} \mathrm{F}\right)$. In contrast, marked differences in both waveform and travel time reflected significant crack formation and spallation of the NETL-1 bond coat as chromia diffused from the Haynes 230 substrate. Efforts are planned to continue to explore the use of the pitch-and-catch and through-transmission acousto-ultrasonic diagnostic techniques for early failure detection of commercial MCrAlY/EBPVD and MCrAlY/APS systems as a function of extended thermal cycling and static oxidation exposure at $1100^{\circ} \mathrm{C}\left(2012^{\circ} \mathrm{F}\right)$. Pending successful demonstration of the acousto-ultrasonic diagnostic technique(s), a portable device for in-situ application will be developed. Efforts are also planned to continue to explore the finite element simulation of the nonlinear acoustic effects to project detection of delamination and changes of material properties in TBC systems.

\section{ACKNOWLEDGEMENTS}

We acknowledge Richard Dennis and Bob Romanosky at DOE NETL for their support. Additionally we acknowledge Jim and Kevin Klotz, Coatings for Industry; Ken Murphy, Ron Honick, Ty Hansen and Bob Grunstra, Howmet International; Shyam Dighe and Ivan Martorell, Westinghouse Plasma Corporation, Tom Taylor, Praxair; and B. Nagaraj, GE, for their efforts during conduct of this project.

The University research efforts were performed in support of NETL under Contract DE-AC2604NT41817.606.01.01, 41817.606.01.08, 41817.606.08.02.107, and 41817.08.07.103.

\section{REFERENCES}

1. R.A.Dennis, "FE Research Direction - Thermal Barrier Coatings and Health Monitoring Techniques," Workshop on Advanced Coating Materials and Technology for Extreme Environments, Pennsylvania State University, State College, PA, September 12 - 13, 2006.

2. G.B.Olson, D.J.Bryan, A.Misra, United States Patent Application Publication No. US 2006/0172142 A1, Aug 23, 2006.

3. D.Mazzotta, M.K.Chyu, M.A.Alvin, "Aerothermal Characterization of Hydrogen Turbines," ASME Turbo Expo 2007, Land, Sea and Air, Montreal, Canada, May 14-17, 2007.

4. M.A.Alvin, F.Pettit, G.Meier, N.Yanar, M.Chyu, D.Mazzotta, W.Slaughter, V.Karaivanov, B.Kang, C.Feng, R.Chen, T-C.Fu, "Materials and Component Development for Advanced Turbine Systems," EPRI 5th International Conference on Advances in Materials Technology for Fossil Power Plants, FL, Oct 3-5, 2007.

5. D.W.Mazzotta, S. Siw, V.Karaivanov, W.Slaughter, M.K.Chyu, and M.A.Alvin, "Gas-Side Heat Transfer in Syngas, Hydrogen-Fired and Oxy-Fuel Turbines,” ASME Turbo Expo 2008, Gas Turbine Technical Congress and Exposition, Berlin, Germany June 11, 2008.

6. V.Karaivanov, D.Mazzotta, W.Slaughter, M.Chyu, and M.A.Alvin, "Three-Dimensional Modeling of Creep Damage in Airfoils for Advanced Turbine Systems," ASME Turbo Expo 2008, Gas Turbine Technical Congress and Exposition, Berlin, Germany, June 12, 2008.

7. C.Feng, M.A.Alvin, B.S-J.Kang, "A Micro-Indentation Method for Assessment of TBC Bond Coat Systems," MS\&T 2007 Conference, Detroit, MI, Sept. 2007. 